\title{
Colônia de Férias do Espaço Movimento: relato de experiência de uma ação multiprofissional
}

\author{
Summer Camp of Espaço Movimento: experience report of a multidisciplinary action
}

\author{
Isabella Carolina Silva Pereira ${ }^{1}$ \\ Ricardo Wagner de Mendonça Trigo ${ }^{1}$ \\ Mayla de Paula Torres Simplício ${ }^{1}$ \\ Paula Pereira de Souza ${ }^{1}$ \\ Renata de Oliveira Castro ${ }^{1}$ \\ Chaiene Caroline de Menezes ${ }^{1}$ \\ Afonso Timão Simplício ${ }^{1}$ \\ Valéria Cristina de Faria ${ }^{2, *}$
}

\section{Resumo}

Objetivo: Apresentar um relato de experiência da primeira e segunda Colônia de Férias do Espaço Movimento, a qual se propõe proporcionar diversão às crianças através da socialização e vivência de novas brincadeiras e atividades fora do seu cotidiano, promover saúde através da abordagem de diversos profissionais da saúde, e por fim, favorecer o desenvolvimento da formação acadêmica dos discentes do curso de Licenciatura em Educação Física da Universidade Federal de Viçosa - Campus Florestal. Métodos: As duas edições da Colônia de Férias do Espaço Movimento foram realizadas em cinco dias da semana durante quatro horas, de 13 às 17 horas, com 100 vagas disponíveis para crianças de 5 a 12 anos, e além da participação dos estudantes do curso de educação física, contou com a colaboração dos seguintes profissionais: educador físico, médico pediatra, enfermeira, odontóloga e nutricionista. Resultados: A primeira edição contou com a participação de 83 crianças e a segunda com a participação de 100 crianças. Conclusão: Foi possível perceber a socialização entre as crianças, resgatando brincadeiras e jogos de rua, a assimilação de algumas práticas de saúde, como higienização e alimentação, e ainda houve a participação e contribuição efetiva dos discentes envolvidos.

Afiliação dos autores

${ }^{1}$ Universidade Federal de Viçosa, Campus Florestal, Florestal, Minas Gerais, Brasil.

${ }^{2}$ Agros - Instituto UFV de Seguridade Social, Florestal, Minas Gerais, Brasil.

\begin{abstract}
Objective: To present an experience report of the first and secondSummer Camp of Espaço Movimento, which a imstoprovide fun to children through socialization and experience of new games andout of yourroutineactivities, promote health through approach various health professional, and ultimately promote the development of the academic training of students of degree in physical education from the Universidade Federal de Viçosa -Campus Florestal. Methods: The twoeditions of the Summer Camp of Espaço Movimentowasheld in five days a week for four hours, from 13 to 17 hours, with 100 places available for children 5-12 years old, and besides the participation of the physicaleducationcoursestudents, counted on the collaboration of the following professionals: physical education teacher, pediatrician, nurse, dentist and a nutritionist. Results: The first edition saw the participation of 83 children and the second with the participation of 100 children. Conclusion: It was possible to realize the socialization among children, rescuing games and street games, the assimilation of some health practices, such as cleaning and feeding, and there was also the participation and effective contribution of the students involved.
\end{abstract}

Keywords: health education, recreation, children.

\section{${ }^{*}$ Autor correspondente}

Rua Zeca Sinhá, 68, casa 3, Bairro Califórnia. Florestal, Minas Gerais, Brasil. CEP: 35.690-000

e-mail:valeriaefiufv@yahoo.com.br

Conflito de interesses

Os autores declararam não haver conflito de interesses.

Processo de arbitragem

Recebido: 19/07/2018 Aprovado: 15/08/2018 


\section{Introdução}

O lazer e o esporte são fatores que associados a um trabalho educativo, contribuem de forma essencial para 0 processo de autonomia humana ${ }^{1}$. Por sua vez, o lazer pode estar relacionado a duas vertentes, a educação para o lazer e a educação pelo lazer ${ }^{2}$

A primeira baseia-se na busca do lazer por conta própria, no qual as pessoas de forma crítica optam por alternativas de lazer variadas. Já a educação pelo lazer é limitada à participação nas atividades, onde o lazer é utilizado para o desenvolvimento pessoal e social, através do prazer na sua realização ou relação com outras pessoas ${ }^{2}$.

Dessa forma, a colônia de férias é um exemplo de educação pelo lazer, pois possibilita oportunidades de vivenciar atividades lúdicas ${ }^{3}$, tornando o brincar para a criança como um modo de expressão, uma maneira de integrar-se ao convívio social. A partir dessas atividades lúdicas, as crianças assimilam valores, adquirem comportamentos e desenvolvem diversas áreas de conhecimento ${ }^{4}$.

Por outro lado, percebe-se que as atividades desenvolvidas na colônia de férias, também se enquadram no conceito de educação para o lazer, pois elas possibilitam que os indivíduos envolvidos se apropriem da sua execução, criando, criticando, vivenciando, refletindo e atuandopoliticamente, quanto a sua participação e empoderamento da prática corporal por elas desenvolvidas $^{5}$

Quando a desvalorização do movimento espontâneo e natural acontece com a criança em virtude do conhecimento formalizado, é eliminado o brinquedo e a ludicidade do espaço de liberdade e exigência da cidadania, ignorando-se as dimensões educativas da brincadeira e do jogo como forma de atividade para estimular a vida social e a atividade construtiva da criança ${ }^{6}$. O jogo é uma das formas que possibilitam os aspectos motores, cognitivos, afetivos e sociais. Nesse caso é importante perceber que é brincando e jogando que a criança organiza o mundo a sua volta, assimilando experiências e informações e, sobretudo, integrando à sua vida atividades, atitudes e valores ${ }^{7}$.

Além disso, a estratégia de atuação multiprofissional se torna uma boa estratégia, pois a educação na infância tem maior relevância quando apresenta envolvimento com atividades práticas e interativas, sendo que hábitos saudáveis em higiene, alimentação e saúde podem ser trabalhados em diversos espaços sociais ${ }^{7}$.

A colônia de férias deve ser tempo-espaço para propagar os valores do lazer, proporcionando oportunidades de exercícios da autonomia e criatividade, de modo que o seu componente lúdico tenha possibilidade de se manifestar e de ser vivenciado ${ }^{3-6}$. Portanto, o objetivo desse estudo é relatar a experiência adquirida durante a primeira e segunda edição da Colônia de Férias do Espaço Movimento.

\section{Métodos}

O Serviço Agros de Atividade Física e Saúde é uma parceria do Agros - Instituto UFV de Seguridade Social (Agros), empresa de plano de saúde e previdência, com a Universidade Federal de Viçosa - Campus Florestal (UFV-CAF).

O Serviço tem como objetivo geral promover saúde e prevenir contra doenças não transmissíveis, e no intuito de atingir um público de diversas idades são desenvolvidas atividades regulares e eventos periódicos que abordem essa temática. A Colônia de Férias do Espaço Movimento ocorre uma vez por ano durante as férias de julho para atender o público infantil.

\section{Colônia de Férias do Espaço Movimento}

A Colônia de Férias do Espaço Movimento teve sua primeira edição entre os dias 20 à 24 de julho de 2015 e a segunda edição nos dias 18 à 22 de julho de 2016. Foram disponibilizadas gratuitamente 100 vagas para as crianças, sendo 50 vagas para beneficiários do AGROS, e 50 vagas para a comunidade de Florestal - MG sem vínculo com o Agros, uma vez que um dos objetivos é explorar a socialização.

A divulgação da Colônia de Férias foi realizada no início do mês de junho com distribuição de folhetos nas escolas e em locais estratégicos. As vagas foram distribuídas conforme figura 1.

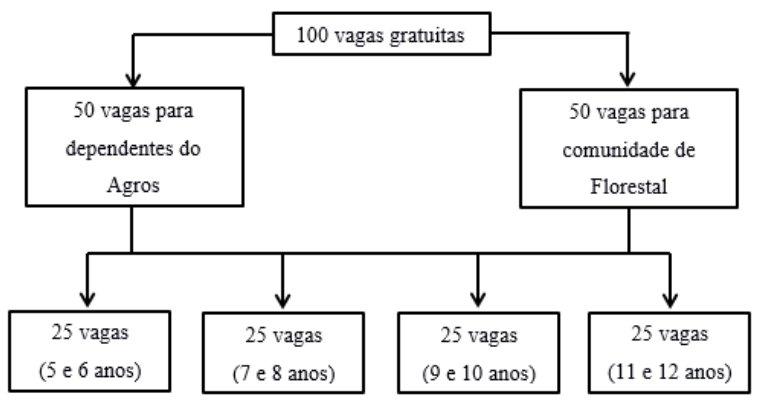

Figura 1. Esquema de distribuição das vagas

Todas as atividades foram realizadas nas dependências da UFV-CAF, sendo divididas em quatro setores (sala de aula, ginásio poliesportivo, campo de futebol e tenda). Deste modo, houve a participação de um coordenador geral do Espaço Movimento, um coordenador da UFV-CAF (professor responsável da disciplina de Recreação e Lazer) e 13 estudantes do curso de Licenciatura em EducaçãoFísica, conforme figura 2.

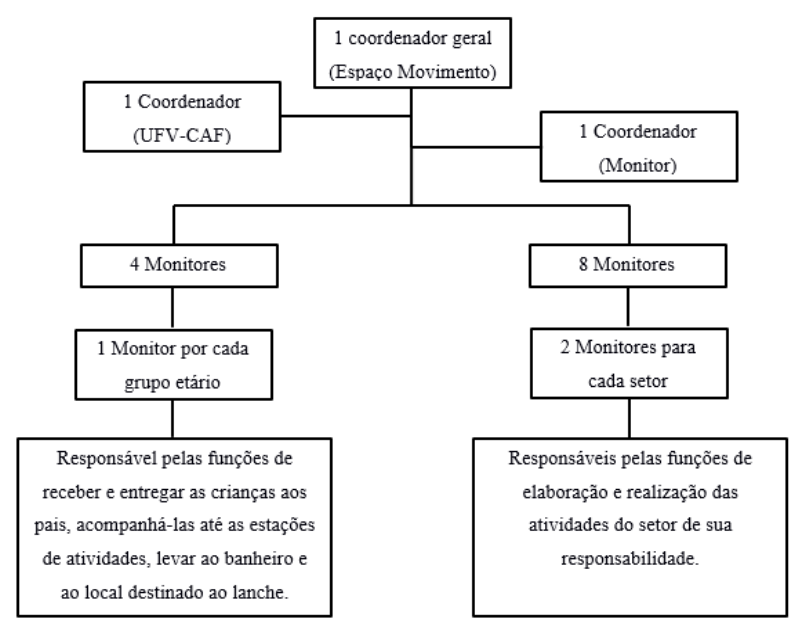

Figura 2. Organograma de tarefas

Durante o desenvolvimento da Colônia de Férias houve intervenções de quatro profissionais da área da saúde com duração de 15 minutos, sendo um profissional de educação física, um médico pediatra, um nutricionista, uma enfermeira e um odontólogo. Essa intervenção aconteceu prioritariamente no momento do lanche das crianças, pois a intenção foi conversar sobre temas importantes para a saúde de maneira descontraída, facilitando assim a atenção e participação das crianças.

\section{Cuidados éticos}

Todos os participantes preencheram a ficha de inscrição com a autorização dos pais/ou responsável. Considerando o cunho de pesquisa a proposta do Espaço Movimento foi apreciada e aprovada pelo Comitê de Ética em Pesquisa com Seres Humanos da Universidade Federal de Viçosa, conforme determina a Resolução no 466/12 do Conselho Nacional de Saúde, sob o parecer número 487.635.

\section{Resultados}

Após autorizações dos pais ou responsáveis a primeira edição da Colônia de Férias do Espaço Movimento contou com participação de 83 crianças e a edição subsequente com participação de 100 crianças. Com relação a amostra, Souza et al. ${ }^{7}$, em estudo semelhante, demonstram que em sua colônia de férias houve a participação de 155 crianças, sendo 83 crianças com idades variando de 5 a 12 anos, todas filhos de servidores da Universidade Federal de Viçosa - Campus Viçosa (UFV CAV). Já no estudo de Silva, Bretas e Caldas $^{8}$ houve a 
participação de 170 crianças, com idades entre 6 e 13 anos, sendo filhos de servidores e alunos da Universidade Federal de Minas Gerais (UFMG).

As crianças desse estudo participaram ativamente das atividades, socializaram e fizeram o principal, se divertiram. Foram realizadas atividades dinâmicas, de raciocínio lógico e interdisciplinares. Arruda e Muller ${ }^{9}$ destacam que o brincar é uma forma de proporcionar às crianças situações que instiguem a imaginação e a criatividade da mesma, de acordo com a orientação do espaço que ela ocupa e materiais disponíveis para as brincadeiras. Além disso, segundo Sousa e Nahas ${ }^{10}$ é importante estimular a prática de atividade física no lazer desde o período escolar com a intenção que esta perdure para o longo da vida.

Em relação aos discentes envolvidos na Colônia de Férias do Espaço Movimento foi uma oportunidade enriquecedora, onde os mesmos tiveram a autonomia de realizar as tarefas, discuti-las e melhorá-las durante o período do evento. Duarte, Marim e Ivo ${ }^{11}$ concluem em seu trabalho que para os discentes, a colônia de férias é um espaço-tempo de formação, onde têm a oportunidade de executar a teoria e prática, pesquisa, ensino e extensão, atuar com o universo infantil, dialogar com as esferas disciplinares e desenvolver um processo educativo coletivo, articulado com a vida social.

\section{Conclusão}

Foi possível perceber a socialização entre as crianças, buscando vivenciar brincadeiras e jogos de rua, instigando a vontade de brincar que é a característica principal de "ser criança". Os assuntos relacionados à saúde discutidos com os profissionais foram abordados de forma satisfatória. Para os discentes envolvidos, a Colônia de Férias foi um espaço para colocar a teoria em prática através dos diversos desafios para ministrar com sabedoria as atividades estabelecidas, e houve a oportunidade de vivenciar um trabalho em conjunto com demais profissionais da área de saúde.

\section{Agradecimentos}

Agradecemos a colaboração de todos os discentes que foram monitores nas duas edições da Colônia de Férias do Espaço Movimento, o apoio integral do Agros e da UFV-CAF, e a todas as crianças que nos deram o prazer de atendê-las.

\section{Referências}

1. Weinberg R. How cancer arises: an explosion of research in 1- Silva KNP. Formação de Trabalhadores em Lazer: por uma educação no e para o tempo livre. Currículo Sem Fronteiras 2013; 13(1): 62-85.

2. Bastos BG, Laurino FC, Furtado GVN, Lemos TG. Colônia De FériasPibidEducaçãoFísica FURG 2013: Uma Experiência no Contexto da Docência. In: $31^{\circ}$ Seminário de Extensão Universitária da Região Sul, 2013; Florianópolis. Florianópolis: Repositório UFSC, 2014.

3. Duarte RN, Ivo AA, Patias BC. Projeto de Extensão Colônia de Férias CEFD/UFSM: relato de experiência. In: $11^{\circ}$ CongresoArgentino Y $6^{\circ}$ Latinoamericano De EducaciónFísica $Y$ Ciencias, 2015; Buenos Aires. Latinoamericano De EducaciónFísica Y Ciencias, 2015; Bueno

4. Najar CL, Alves OO. Atividades Lúdicas Como Mediadoras Do Letramento No Espaço Da Educação Infantil. Disciplinar um Scientia: Série: CiênciasHumanas 2004; 5(1): 107-124.

5. Padilha V. Dialética do Lazer. 1.ed. São Paulo: Boitempo 2006; v.1; 288p.

6. Nunes ALR, Becker, LS. Corpo, Movimento e Ludicidade: uma contribuição ao processo de alfabetização. Revista do Centro de contribuição ao processo de

7. Souza RAF, Nunes EM, Lima JL, Vieira NC, Priore SE, Silva RP. Colônia de férias: um espaço social a ser explorado pela saúde? Revista Elo 2014 3(1): 1-8.

8. Silva SR, Bretas P, Caldas CDPC. Colônia de Férias: Uma Experiência de Formação. Kinesis 2012; 30(2): 93-102.

9. Arruda FM, Muller VR. Brincadeiras e Espaços Urbanos: Um Estudo da Prática Lúdica de Crianças de Diferentes Classes Sociais da Cidade de Maringá - PR. Brincadeiras e Espaços Urbanos 2010; 13(4): 1-6.

10. Sousa TF, Nahas MV. Inatividade física no lazer pregressa e atual em estudantes universitários brasileiros. Arquivos de Ciências do Esporte 2014; 1(1): 33-36.

11. Duarte RN, Marin EC, Ivo AA. Colônia de Férias como Projeto de Extensão Universitária. Biomotriz 2014; 8(2): 1-14. 